\title{
Biomechanical factor affecting Baseball Pitching Velocity.
}

\author{
Ryoga Kuriyama ${ }^{1}$, Yasushi Ota ${ }^{2}$ \\ ${ }^{1}$ Asahi Group Holdings, LTD. Kyushu branch for Chain Stores Sales Section for Chain \\ Stores II, Fukuoka, Japan \\ ${ }^{2}$ Department of Management Okayama University of Science, Okayama, Japan
}

\begin{abstract}
In baseball, pitchers have a central role and high-speed pitching is desirable. So far, several studies of the physical factors related to pitching form with the aim of improving the speed of pitched balls have been conducted. In this study, we used a motion capture to acquire threedimensional (3D) time series data related to the speed of pitched balls and performed a kinetics analysis by using these acquired data. The acquired data were divided into five pitching phases: wind up, early cocking, late cocking, acceleration, and follow through. Our analysis identified the body parts that contribute to increasing the speed of pitched balls, i.e., the speed of rotation of individual joints and the timing/phase when power can be applied. Especially, by examining joint angular velocity and joint force, we showed that the speed of pitched balls is determined by the action of the upper limbs as well as the coordinated action of the whole body, particularly the lower limbs and the trunk.
\end{abstract}

\section{Keywords (five)}

Kinetic analysis; Motion capture; Multiple regression analysis; Baseball.

\section{DOI}

10.31236/osf.io/bdf93

\section{Citation}

Ryoga, Kuriyama, Yasushi Ota (2019).

Biomechanical factor affecting Baseball Pitching Velocity.

SportRxiv. doi: 10.31236/osf.io/bdf93

\section{Introduction}

Pitcher has a central role in baseball game. It is said that pitchers bear $80 \%$ of the responsibility of performance in any team, because a team cannot lose if no runs are conceded to their opponents. High-speed pitching is a highly desirable quality in a pitcher. Therefore, investigations regarding the physical factors related to pitching form have been conducted with the aim of improving the speed of pitched balls.

In the 1970's the Soviet Union started on using different weighted implements as training programs for Olympic athletes ([5], [8], [9]). Based on this concept, the training programs were developed specifically for baseball. In these programs, balls have been used ranging from 3 ounces to 21 ounces to increase throwing velocity ([1], [2], [3], [6], [7]).

In this study, we investigated the effect of training with combinations of standard, heavy, and light baseballs (weighted ball: 6 ounces; standard ball: 5 ounces; and light ball: 4 ounces) on pitching velocity and mechanism. Our training duration and pitch counts were adjusted on the basis of a study by DeRenne 
[4] (Group 1); our training was defined, and was considered the object of analysis throughout training. The following effects of this training regimen were expected. Light balls were expected to improve participants' pitching speed because the lower weight caused rapid stimulation of the nervous system, which in turn commands rapid motion in muscles related to pitching. Conversely, weighted balls were expected to strengthen muscles related to pitching.

In this study, we verified an effect of our proposed training and performed kinetics analysis to acquire three dimensional (3D) time series data related to the speed of pitched balls, and the speed of rotation of each joint relevant to the speed of pitched balls were determined via multiple regression analysis.

\section{Methods.}

\subsection{Experimental methods}

\section{Experiment 1}

University pitchers $(\mathrm{n}=\mathbf{2 8})$ were tested for pitching velocity, and randomly assigned to two groups, A and B. Group A $(n=13)$ undertook our training 3 days per week for 20 weeks. Group B $(n=15)$ underwent normal training. Before and after each training, the participants made 10 throws of normal weight balls to a catcher seated $18.44 \mathrm{~m}$ from a pitcher's plate at pre-determined order, after performing a sufficient warmup. The pitched ball speed was measured for each attempt.

\section{Experiment 2}

Throughout the pitching motion, 3D positional data on the body was acquired using motion capture of 13 pitchers in Group A from the university baseball team who provided informed consent to participate. After performing a sufficient warm-up, the participants made 6 throws of three weighted baseballs to a catcher seated $18.44 \mathrm{~m}$ from a virtual pitcher's plate at pre-determined order, and the $3 \mathrm{D}$ motion was recorded by motion capture. The pitched ball speed was measured for each attempt and $3 \mathrm{D}$ positional data acquired during throws of a standard ball were used in the analysis in this study.

\subsection{Acquired data in Experiment 2}

In Experiment 2, we analyzed the data of joint angular velocity and force. Time series data items were captured every $0.002 \mathrm{~s}$ for a maximum of $500 \mathrm{~s}$. Moreover, each data item was computed from a musculoskeletal model created using SIMM. The computed data was divided into five pitching phases (wind up, early cocking, late cocking, acceleration, and follow through) for each participant, and they were analyzed after considering the average value as the index. For further information on the setup of a coordinate system and the calculation of kinetics parameters, please refer to our previous research.

\subsection{Methods of analysis in Experiment 2}

A multiple linear regression was calculated to predict the speed of pitched balls based on angular velocity and joint force. And we created regression models to investigate the body parts contributing to an improvement in pitching speed and their contributory mechanisms. In addition, a regression model was created to obtain correlations between the speed of a pitched ball and join angular velocity/joint force during 4 phases of pitching excluding wind up, which exhibited a poor relationship. Therefore, the regression analysis acquired 8 formulae during 4 phases for both angular velocity and joint force.

\section{Results}

\subsection{Experiment 1}

Figure 1 show the result of the change the pitching velocity between Groups A and B before and after training. From Figure 1 and the p-value (0.00246) for the paired samples t-test which is less than 0.05, the effect of our training was demonstrated by comparing the change in pitching velocity between Groups A and B 
before and after training.

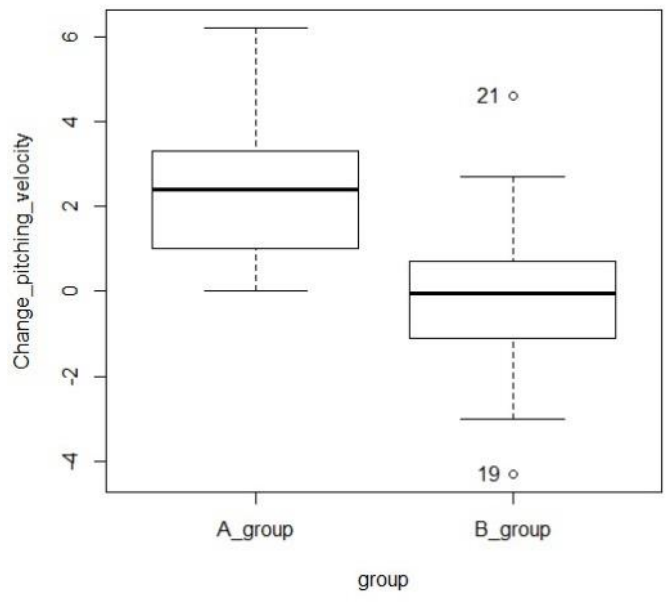

Figure 1. Boxplot of the change the pitching velocity $A$ and $B$.

\subsection{Experiment 2}

\subsubsection{Angular velocity}

\section{Early cocking}

Table 1 show the results of multiple linear regression analysis, where we used the AIC (Akaike Information Criterion) for selecting variables in multiple linear models. A significant regression equation was found $(\mathrm{F}(10,65)=12.76, \mathrm{p}<.001)$, with an adjusted $\mathrm{R}^{2}$ of .6107 .

Table1. Results of multiple linear regression analysis.

\begin{tabular}{|l|l|l|l|l|}
\hline \multicolumn{7}{|c|}{ Early cocking } \\
\hline Coefficients: & Estimate & Std. Error & $\mathrm{t}$ value & $\operatorname{Pr}(>|\mathrm{t}|)$ \\
\hline (Intercept) & 118.3947 & 0.5245 & 225.713 & $<.001^{* * *}$ \\
\hline lumbar pitch & 0.835 & 0.6068 & 1.376 & 0.173526 \\
\hline right ankle flex & -1.1231 & 0.6176 & -1.818 & 0.073614 \\
\hline left hip add & 1.2399 & 0.5857 & 2.117 & $0.038081^{*}$ \\
\hline left hip flex & 1.3799 & 0.7231 & 1.909 & 0.060743 \\
\hline right hip flex & -1.7425 & 0.7018 & -2.483 & $0.015622^{*}$ \\
\hline left knee flex & -2.185 & 0.6315 & -3.46 & $<.001^{* * *}$ \\
\hline lumbar roll & -0.9821 & 0.6101 & -1.61 & 0.112296 \\
\hline lumbar yaw & 2.6948 & 0.7532 & 3.578 & $<.001^{* * *}$ \\
\hline right shoulder elevation & 3.2076 & 0.6273 & 5.114 & $<.001^{* * *}$ \\
\hline right wrist flexion & 1.0397 & 0.6248 & 1.664 & 0.100944 \\
\hline
\end{tabular}

Significance codes: ${ }^{*} \mathrm{p}<.05,{ }^{* *} \mathrm{p}<.01,{ }^{* * *} \mathrm{p}<.001$ 


\section{Late cocking}

Table 2 show the results of multiple linear regression analysis, where we used the AIC for selecting variables in multiple linear models. A significant regression equation was found $(F(8,56)=19.5, p<.001)$, with an adjusted $\mathrm{R}^{2}$ of .6981.

Table 2. Results of multiple linear regression analysis.

\begin{tabular}{|l|l|l|l|l|}
\hline \multicolumn{7}{|c|}{ Late cocking } \\
\hline Coefficients: & Estimate & Std. Error & $\mathrm{t}$ value & $\operatorname{Pr}(>|\mathrm{t}|)$ \\
\hline (Intercept) & 119.4923 & 0.5004 & 238.814 & $<.001^{* * *}$ \\
\hline right ankle flex & -5.1247 & 0.6876 & -7.453 & $<.001^{* * *}$ \\
\hline right elbow flexion & 0.7792 & 0.5448 & 1.43 & 0.15821 \\
\hline right hip add & -3.1168 & 0.7247 & -4.301 & $<.001^{* * *}$ \\
\hline right hip flex & 1.8342 & 0.6765 & 2.711 & $0.00889^{* *}$ \\
\hline right knee flex & 3.6133 & 0.6966 & 5.187 & $<.001^{* * *}$ \\
\hline lumbar yaw & -2.2895 & 0.8882 & -2.578 & $0.0126^{*}$ \\
\hline right shoulder rotation & -5.8807 & 0.8973 & -6.554 & $<.001^{* * *}$ \\
\hline right wrist flexion & 1.238 & 0.6457 & 1.917 & 0.06032 \\
\hline
\end{tabular}

Significance codes: ${ }^{*} \mathrm{p}<.05,{ }^{* *} \mathrm{p}<.01,{ }^{* * *} \mathrm{p}<.001$

\section{Acceleration}

Table 3 show the results of multiple linear regression analysis, where we used the AIC for selecting variables in multiple linear models. A significant regression equation was found $(F(8,69)=14.45, p<.001)$, with an adjusted $\mathrm{R}^{2}$ of .5829.

Table 3. Results of multiple linear regression analysis.

\begin{tabular}{|l|l|l|l|l|}
\hline \multicolumn{5}{|c|}{ Acceleration } \\
\hline Coefficients: & Estimate & Std. Error & t value & $\operatorname{Pr}(>|\mathrm{t}|)$ \\
\hline (Intercept) & 118.9359 & 0.5024 & 236.722 & $<.001^{* * *}$ \\
\hline left hip add & -1.1793 & 0.6371 & -1.851 & 0.0684 \\
\hline left hip flex & -1.6378 & 0.947 & -1.729 & 0.0882 \\
\hline right hip flex & 1.8162 & 0.9739 & 1.865 & 0.0664 \\
\hline left knee flex & 3.1362 & 1.2065 & 2.599 & $0.0114^{*}$ \\
\hline lumbar roll & -2.9453 & 0.637 & -4.624 & $<.001^{* * *}$ \\
\hline right shoulder elevation & 1.5318 & 0.6113 & 2.506 & $0.0146^{*}$ \\
\hline right shoulder rotation & -2.9961 & 0.7223 & -4.148 & $<.001^{* * *}$ \\
\hline
\end{tabular}


Biomechanical factor affecting Baseball Pitching Velocity

\begin{tabular}{|l|l|l|l|l|}
\hline right subt angle & 4.9193 & 0.7436 & 6.616 & $<.001^{* * *}$ \\
\hline
\end{tabular}

Significance codes: ${ }^{*} \mathrm{p}<.05,{ }^{* *} \mathrm{p}<.01,{ }^{* *} \mathrm{p}<.001$

\section{Follow through}

Table 4 show the results of multiple linear regression analysis, where we used the AIC for selecting variables in multiple linear models. A significant regression equation was found $(\mathrm{F}(12,56)=7.258, \mathrm{p}<.001)$, with an adjusted $\mathrm{R}^{2}$ of .5248 .

Table 4. Results of multiple linear regression analysis.

\begin{tabular}{|l|l|l|l|l|}
\hline \multicolumn{5}{|c|}{ Follow through } \\
\hline Coefficients: & Estimate & Std. Error & t value & $\operatorname{Pr}(>|t|)$ \\
\hline (Intercept) & 118.6812 & 0.5637 & 210.551 & $<.001^{* * *}$ \\
\hline left hip add & 2.1036 & 0.8787 & 2.394 & $0.020044^{*}$ \\
\hline right hip add & 2.9279 & 0.9718 & 3.013 & $0.00383^{* *}$ \\
\hline left hip flex & 5.6498 & 1.4949 & 3.779 & $<.001^{* * *}$ \\
\hline right hip flex & -2.6884 & 1.548 & -1.737 & 0.087953 \\
\hline left knee flex & -6.4734 & 1.3043 & -4.963 & $<.001^{* * *}$ \\
\hline right knee flex & 4.6115 & 1.1773 & 3.917 & $<.001^{* * *}$ \\
\hline lumbar roll & -3.8781 & 0.9629 & -4.027 & $<.001^{* * *}$ \\
\hline right pro supination & -1.7619 & 0.6802 & -2.59 & $0.012207^{*}$ \\
\hline right shoulder elevation & -2.124 & 0.7456 & -2.849 & $0.006131^{* *}$ \\
\hline right shoulder rotation & -1.1131 & 0.7615 & -1.462 & 0.14943 \\
\hline right subt angle & 2.7308 & 0.7203 & 3.791 & $<.001^{* * *}$ \\
\hline right wrist deviation & 1.5117 & 0.6832 & 2.213 & $0.031018^{*}$ \\
\hline
\end{tabular}

Significance codes: ${ }^{*} \mathrm{p}<.05,{ }^{* *} \mathrm{p}<.01,{ }^{* *} \mathrm{p}<.001$

\subsubsection{Joint force}

\section{Early cocking}

Table 5 show the results of multiple linear regression analysis, where we used the AIC for selecting variables in multiple linear models. A significant regression equation was found $(F(8,56)=12.91, p<.001)$, with an adjusted $\mathrm{R}^{2}$ of .5983 . 
Biomechanical factor affecting Baseball Pitching Velocity

Table 5. Results of multiple linear regression analysis.

\begin{tabular}{|l|l|l|l|l|}
\hline \multicolumn{7}{|c|}{ Early cocking } \\
\hline Coefficients: & Estimate & Std. Error & $t$ value & $\operatorname{Pr}(>|\mathrm{t}|)$ \\
\hline (Intercept) & 119.9385 & 0.5555 & 215.901 & $<.001^{* * *}$ \\
\hline right clavicle joint force $\mathrm{x}$ & 2.2593 & 0.8089 & 2.793 & $0.00713^{* *}$ \\
\hline left femur joint force y & 2.8267 & 1.6149 & 1.75 & 0.08553 \\
\hline right femur joint force y & -1.1879 & 0.729 & -1.629 & 0.10883 \\
\hline right foot joint force y & -2.6829 & 1.0126 & -2.65 & 0.01046 \\
\hline right hand joint force y & -4.4085 & 0.7403 & -5.955 & $<.001^{* * *}$ \\
\hline right humerus joint force y & 2.9234 & 1.3258 & 2.205 & $0.03158^{*}$ \\
\hline left tibia joint force y & 3.9869 & 0.6541 & 6.095 & $<.001^{* * *}$ \\
\hline right tibia joint force y & -3.0003 & 1.2849 & -2.335 & $0.02315^{*}$ \\
\hline
\end{tabular}

Significance codes: ${ }^{*} \mathrm{p}<.05,{ }^{* *} \mathrm{p}<.01,{ }^{* * *} \mathrm{p}<.001$

\section{Late cocking}

Table 6 show the results of multiple linear regression analysis, where we used the AIC for selecting variables in multiple linear models. A significant regression equation was found $(\mathrm{F}(5,78)=19.56, \mathrm{p}<.001)$, with an adjusted $\mathrm{R}^{2}$ of .5279 .

Table 6. Results of multiple linear regression analysis.

\begin{tabular}{|l|l|l|l|l|}
\hline \multicolumn{5}{|c|}{ Late cocking } \\
\hline Coefficients: & Estimate & $\begin{array}{l}\text { Std. Er- } \\
\text { ror }\end{array}$ & $t$ value & $\operatorname{Pr}(>|t|)$ \\
\hline (Intercept) & 118.8452 & 0.5347 & 222.251 & $<.001^{* * *}$ \\
\hline left femur joint force y & 1.0073 & 0.6176 & 1.631 & 0.10689 \\
\hline right femur joint force y & -2.2693 & 0.7841 & -2.894 & $0.00493^{* *}$ \\
\hline right humerus joint force y & 1.8272 & 0.7534 & 2.425 & $0.01761^{*}$ \\
\hline left tibia joint force y & -4.3197 & 0.6644 & -6.502 & $<.001^{* * *}$ \\
\hline torso joint force $\mathrm{x}$ & 1.3762 & 0.6084 & 2.262 & $0.02649^{*}$ \\
\hline
\end{tabular}

Significance codes: ${ }^{*} \mathrm{p}<.05,{ }^{* *} \mathrm{p}<.01,{ }^{* *} \mathrm{p}<.001$ 


\section{Acceleration}

Table 7 show the results of multiple linear regression analysis, where we used the AIC for selecting variables in multiple linear models. A significant regression equation was found $(F(6,66)=26.79, p<.001)$, with an adjusted $\mathrm{R}^{2}$ of .6825 .

Table 7. Results of multiple linear regression analysis.

\begin{tabular}{|l|l|l|l|l|}
\hline \multicolumn{7}{|l|}{ Acceleration } \\
\hline Coefficients: & Estimate & Std. Error & t value & $\operatorname{Pr}(>|t|)$ \\
\hline (Intercept) & 118.9863 & 0.4626 & 257.194 & $<.001^{* * *}$ \\
\hline right femur joint force y & 3.2108 & 0.5962 & 5.386 & $<.001^{* * *}$ \\
\hline right foot joint force y & -3.4329 & 0.7067 & -4.858 & $<.001^{* * *}$ \\
\hline right scapula joint force x & -3.5922 & 0.7477 & -4.804 & $<.001^{* * *}$ \\
\hline left tibia joint force y & 5.107 & 0.9149 & 5.582 & $<.001^{* * *}$ \\
\hline torso joint force $\mathrm{x}$ & 1.6602 & 0.8116 & 2.046 & $0.0448^{*}$ \\
\hline right ulna joint force y & 1.8591 & 0.681 & 2.73 & $0.00811^{* *}$ \\
\hline
\end{tabular}

Significance codes: ${ }^{*} \mathrm{p}<.05,{ }^{* *} \mathrm{p}<.01,{ }^{* * *} \mathrm{p}<.001$

\section{Follow through}

Table 8 show the results of multiple linear regression analysis, where we used the AIC for selecting variables in multiple linear models. A significant regression equation was found $(\mathrm{F}(6,72)=18.97, \mathrm{p}<.001)$, with an adjusted $\mathrm{R}^{2}$ of .5802 .

Table 8. Results of multiple linear regression analysis.

\begin{tabular}{|l|l|l|l|l|}
\hline \multicolumn{7}{|l|}{ Follow through } \\
\hline Coefficients: & Estimate & Std. Error & $\mathrm{t}$ value & $\operatorname{Pr}(>|\mathrm{t}|)$ \\
\hline (Intercept) & 119.2532 & 0.5154 & 231.386 & $<.001^{* * *}$ \\
\hline right clavicle joint force $\mathrm{x}$ & -3.8837 & 0.5825 & -6.667 & $<.001^{* * *}$ \\
\hline left femur joint force y & -1.2836 & 0.5795 & -2.215 & $0.029923^{*}$ \\
\hline left foot joint force y & 2.8041 & 0.5878 & 4.77 & $<.001^{* * *}$ \\
\hline right foot joint force y & 0.8916 & 0.5871 & 1.519 & $0.133^{* 24}$ \\
\hline torso joint force $\mathrm{x}$ & -1.9643 & 0.5497 & -3.573 & $<.001^{* * *}$ \\
\hline right ulna joint force y & 2.2315 & 0.6086 & 3.666 & $<.001^{* * *}$ \\
\hline
\end{tabular}

Significance codes: ${ }^{*} \mathrm{p}<.05,{ }^{* *} \mathrm{p}<.01,{ }^{* * *} \mathrm{p}<.001$ 
4. Discussion

\subsection{Angular velocity}

\section{Early cocking}

The coefficients of right shoulder flexion, lumbar yaw, and left knee flexion were large. These results suggest that rapidity of these movements increases the speed of pitched baseballs. Moreover, our results suggested that the generation of angular velocity in the joints of the trunk and upper limbs through the necessary movements in the lumbar region leads to an improvement in the speed of pitched baseballs, as shown by the large coefficient of lumbar yaw.

\section{Late cocking}

Left ankle flexion, left knee flexion, left hip adduction, and left hip flexion are considered to produce rotation. Therefore, conscious rotation of the pivoting foot is required to improve the speed of pitched baseballs during late cocking.

\section{Acceleration}

The "whip" movement of the upper limb is related to the speed of pitched baseballs, as shown by the large coefficient of right shoulder flexion and right shoulder rotation. It is thought that the motion of the lower limb and trunk in the phase before this is important, because these motions are not performed consciously but occur as a consequence of the "whip" movement chain.

\section{Follow through}

The angular velocity of the trunk and lower limbs was found to influence the speed of pitched baseballs. Therefore, the speed of pitched baseballs can be increased by a conscious kick of the right lower limb and straddling with the left lower limb.

\subsection{Joint force}

\section{Early cocking}

Putting weight down firmly on the lower limbs was shown to increase the speed of pitched baseballs, evident in the fact that the coefficients of the tibia and foot were large. Moreover, the outward swing movement was also shown to influence the speed of pitched baseballs, because the coefficients of the left femur and tibia were large.

\section{Late cocking}

The speed of a pitched ball increases as a result of the power generated in the lower limb being transmitted to the proximal portion of the upper limbs, because the coefficients of these regions were large.

\section{Acceleration}

A strong kick of the pivoting foot was determined to affect the speed of pitched baseballs, evident in the large coefficients of the right femur and foot.

\section{Follow through}

The speed of the arm at the release increases, suggesting that the speed of pitched baseballs can be increased by straddling of the left lower limb until the shaking off of the right arm, because the coefficients of the left femur and foot were large.

\section{Conclusion}

In this study, we identified the body parts that contribute to the increase in the speed of pitched baseballs; i.e., the speed of rotation of individual joints and the timing/phase when power can be applied. By 
examining joint angular velocity and joint force, we showed that the speed of pitched baseballs is determined by the action of the upper limbs as well as the coordinated action of the whole body, particularly the lower limbs and the trunk. Although we performed regression analysis using selected variables related to joint angular velocity and joint force, a better regression analysis may be possible using other variables and must be undertaken in future. Moreover, a more accurate result may be obtained with a regression analysis that takes into consideration the effects of successive pitching.

\section{REFERENCES}

1. Bagonzi, J. A. (1978). "The effects of graded weighted baseballs, free weight training, and simulative isometric exercise on the velocity of a thrown baseball (Unpublished master's thesis)", Indiana University, Bloomington, IN.

2. Brose, D. E., and Hanson, D. L. (1967). "Effects of overload training on velocity and accuracy of throwing”, Research Quarterly, 38(4), 528-533.

3. DeRenne, C., Ho, K., and Blitzblau, A. (1990). Effects of weighted implement training on throwing velocity, Journal of Applied Sport Science Research, 4, 16-19.

4. DeRenne, C., Buxton, B. P., Hetzler, R. K., and Ho, K. W. (1994). Effects of under- and over-weighted implement training on pitching velocity, Journal of Strength and Conditioning Research, 8(4), 247250.

5. Konstantinov, O. (1979). Training program for high level javelin throwers, Soviet Sports Review, 14(3), 130-134.

6. Litwhiler, D., and Hamm, L. (1973). Overload: Effect on throwing velocity and accuracy, Athletic Journal, 53, 64-65.

7. Logan, G. A., McKinney, W. C., Rowe, J. W., and Lumpe, J. (1966). Effect of resistance through a throwing range of motion on the velocity of a baseball, Perceptual and Motor Skills, 23(1), 55-58.

8. Vasiliev, L. A. (1983). Use of different weight to develop specialized speed-strength, Soviet Sports Review, 18(1), 49-52.

9. Verkhoshansky Y., and Tatyan V. (1983). Speed-strength preparation of future champions, Soviet Sports Review, 18(4), 166-170. 